\title{
Research on Cross-Cultural Elements in Japanese-Chinese Interpreting Practices
}

\author{
Shuwei Wang ${ }^{1, a}$ \\ ${ }^{1}$ College of Foreign Studies, University of Science and Technology, Beijing, China, 100000 \\ aemail,
}

Keywords: Trans-Culture; Business Japanese; Reconstruction

\begin{abstract}
With an increasing number of Japanese companies stationed in China, business interpreting activities between Chinese and Japanese are becoming more and more frequent. At present, the cultural gaps between the two countries have somehow hindered the smooth proceeding of business activities. In view of this, the focus of translation has gradually been shifted from the equivalent transformation of words to the cross-cultural understanding of comparative cultures. This study tries to classify phenomenon of cultural losses in business Japanese interpreting practices, with an aim of expounding how the translator ensures a smooth translation of information and interpersonal commitments through the reconstructing of communicative contexts.
\end{abstract}

\section{Introduction}

In the 21st century, Japanese enterprises have been embodied in the deepening globalization process, of which a considerable number have built their branches in China. According to the data from Japan's Teikoku Databank reported by Japanese Economic News, by the end of August 2012, the number of Japanese company branches in China had reached 14,394, most of which are from Tokyo, reaching 4748. In addition, 24 Japanese prefectures and countries arranged their branches in China, with over 100 companies belonging to each one of them. As for the industrial distribution, industrial resin product, auto part and other manufacturing companies rank the highest, with an amount of 5951. Industrial electrical equipment and clothing companies come as the second, with a total of 5057. The rest parts include: 1868 in service industry, 439 in retail industry, 402 in transport and communications, 305 in the construction, 153 in real estate and 219 in other industries.

The data above shows the frequency of business communication between Japan and China. However, business trades between the two countries can not be managed well without interpreters, whose responsibility is to eliminate linguistic and cultural barriers between the Japanese and Chinese people in the course of business activities. A good business interpreter should master not only the two languages and disciplinary knowledge in related fields, but also the cultural backgrounds of the two countries. Translation is not a simple process of language transfer and correspondence, and business activities cannot be isolated from communicative and cultural contexs. Both require interpreters to have a deep understanding of linguistic, cultural, social, ethnic and other aspects of knowledge. Currently, the cultural gaps between the two countries have somehow hindered the smooth proceeding of business activities, so the translation view in academic fields has not only stayed in word-to-word conversion, but has focused on the equivalent transformation of cultural level. In the book Cultural Default and Coherence Reconstruction in Translation (Wang Dongfeng, 1997: 55), Wang pointed out, "in communication, it is necessary for the interlocutors to have a shared background knowledge or pragmatic presupposition in order to achieve the intended purpose of communication .With the understanding of this common knowledge or pragmatic presupposition, we can omit the redundant explanations for both sides to improve communication efficiency." The term "shared background knowledge" is not only a languistic one, but rather the cultural background knowledge. 
China and Japan are neighbors separated only by a strip of water, with long history of exchanges. However, they are two different countries and it is inevitable to have divergences between the two languages, cultures, national values, and ideologies. This paper attempts to classify and analyze the cultural losses in the examples of business Japanese textbook? , and suggest how an interpreter could restructure the context to ensure the smooth implementation of translation process.

\section{Cultural Loss and Reconstruction on Verbal Level}

As we all know, different languages have different features, and the inequivalence of language structure between source language and target language often occurs. If translators aren't aware of this kind of non-equivalence, they are likely to cause information omission and incomplete translation. For example, they should pay attention to the absence of subject in Japanese language structure.

In Japanese, the first person is often omitted for many reasons. It can be determined by the meaning of the predicate, the expressive characteristics of giving and receiving sentence, as well as the idiomatic expression of honorifics. Such examples are made below.

The meaning of predicate determines subject omission:

TIanzhong: I want to go to Dahe commercial organization this afternoon

Leader: Go ahead

The subject "I” doesn't appear in the first sentence because of predicate verb "want around”. In Japanese, desire auxiliary verb can only be used for first person expression. As a result, first person will be omitted as long as "Thailand" appears as part of predicate verb. However, translators have to find out the first person and translate it into other languages. There are similar verbs as "think" (I want to, I think) which indicate the mental activity of first person and adjectives which express the emotions of first person, for instance, delightful, like and dislike, etc.

The expression of giving and receiving sentences determine the subject omission:

TIanzhong:_Let me do this transport work

Quyinxian: Then please

This giving and receiving sentence it can be translated into "please let me" or "please allow me", so first person is not necessary.

The idiomatic expression of honorifics results in subject omission:

Tianzhong: I'm in a tram, and it will be about 10mins before I reach where you are)

Quyinxian: Ok, we'll be waiting for you

"We look forward for you" above are words of self-abasement, which can only be used on one's own or one's own side, so subject is often omitted when such words or sentences appear.

As shown above, the subject of the first person is often omitted in Japanese. If we look at the omission on cultural level, we will find the main reason is that Japanese people don't like to emphasize themselves. One notable feature of Japanese culture is that they put community above themselves. In addition, second person as subject is often omitted in Japanese, because they think it is impolite to call others "you”, they will add such as in order to replace "you”. Therefore, this point should attract interpreters' attention.

\section{Cultural Loss and Reconstruction on Idiomatic Expression Level}

Japanese are quite different from Chinese in expression habits and which is caused by the geographical environment of the country. It is located on the island, together with its closed-door policy before Meiji Restoration, making its living environment rather closed. As a result, Japanese 
developed a similar lifestyle and ways of thinking with such a living environment, and sometimes they can understand each other without saying it.

The Ambiguous Expression Used In Refusal. Japanese learners should know that Japanese avoid refusing others directly, especially in business settings. They usually maintain business ties through interpersonal relationships, so they hardly refuse directly to avoid hurting each other. Specifically, they seldom use the "blunt words" such as "no" "no way", instead, they prefer more ambiguous expressions.

Tianzhong: The price is 250 dollars because of special packaging

Quyinxian: It seems a little expensive. Can it be cheaper?

Tianzhong: This is the price with a calculation of the cost. But let us think about it again and contact you later.

"seem like" in the sentence above is a kind of expression to protest euphemisticly while "let us think about it" the answer is most likely an indirect refusal. Especially when a frown or embarrassing look is shown on the speaker's face, there will be little hope for bargainning. Here, translators can judge by the speaker's expression. If the price reduction is possible, generally, Tianzhong will say "we'll consider it positively", and maybe he will give a more detailed explanation. On this occasion, business Japanese translators should restructure the sentence to avoid the loss of time.

Positive Answer, the Way to Avoid Absolute Answer. The expression of "think".

Leader: Where is Yamamura?

Tianzhong: He went out in the morning, and he should be in Daiwacommercial organization

"I think" belongs to this kind of expression. Besides, there are similar expressions such as “considered”, "I think that” etc.

Tianzhong: Our new commodity will be sent to you in two or three days

Quyinxian: Really? I'm looking forward to it.

"I think”, “considered ", “I think that” in the sentence above need no translation, that is , we don't have to translate "I think" into "I think" or "I want", “considered ", "I think that "into “ be considered by everyone here".

Chinese businessmen with little knowledge about Japanese will be confused if these special expressions are translated laterally. Thus, translators should translate reasonably based on a precise understanding of these expressions.

\section{Cultural Loss and Reconstruction on Nonverbal Communication Level}

Nonverbal communication includes body language (action on the head, face, eye, hand, leg, etc.), paralanguage (silence, turn-taking, non-speech sound, etc.) and object language( skin color, hair, body ordor, clothing, makeup, etc.) Japanese prefer nonverbal communication, because the common environment they live in and similar ways of thinking make it easier for them to understand each other with gestures. There is one cultural practice in Japan called "observe" culture, to which Japanese attach much importance especially in business affairs.

"Observe" is to understanding each other's intention and need through observing the changes of body psoes or facial expressions. Almost all Japanese business people possess a good mastery of this skill. They can often deduce the intentions and needs of their business partners from little information since they can fulfill the rest themselves. Thus there is often a high degree of tacit understanding in Japanese business affairs. However, there is no "observe" in Chinese culture. Some businessmen have no idea about it either. As a result, business affairs often end up a failure. Therefore, interpreters are supposed to deeply understand Japanese "observe" culture and catch the 
nonverbal information to make sure the commercial communication carry on smoothly through reconstructing the loss of the source culture on the nonverbal communication level. Here are several types of Japanese body language frequently used in business activities.

Bow. Japanese people take greeting as a fundamental concept for human beings. It would be emphasized countless times from their childhood, even after they enter society, whether at home, school or in workplace. Thus, greeting has been deeply-rooted in the hearts of Japanese people as part of their lives. Of course, greetings are not the same in different time and on different occasions. But no matter what occasion it is, their body languages are basically the same, and a nod and a bow are commonly made in their greetings.

It is rather formal when Japanese business people greet Chinese clients for the first time, and they will use Japanese ways of greeting through body languages. In their greetings, bow is a much important form of nonverbal communication. Firstly introduced from China, bow is preserved as a greeting body language in Japan. Japanese people express welcome and respect through bow so that Japanese people are always polite in the eyes of most foreigners. There are several forms of bow, among which the one requiring 30-degree bending of the upper body is often used in business activities. In Japan, bow is considered the most basic form in business etiquette, so bow is part of the induction trainings for new employers.

Nod with a Smile. In business negotiations, Japanese usually smile and nod, which leaves a false impression on Chinese companies that their Japanese counterparts have agreed on their terms and the negotiations go well. However, these gestures just show that they are listening politely, few of which actually means recognition. Japanese often use some pet phrases like "so"、"I see” when they nod to show they're willing to listen. If they nod to show agreement, then they usually repeat what they agree on and continue to confirm the agreement of both parties. Interpreters need to observe and analyze this situation to ensure the accuracy of the target language.

Silence. In his book Intercultural Nonverbal Communication, Bi(2004:46) considers that silence is one of the paralinguistic phenomenon, which means "not make one's position clearly in speech and conversation, rather to make a silent response or pause." It is common in business activities, especially the Japanese ones, but it means more than what we have mentioned. Sometimes it means approval, sometimes protest, and sometimes hesitation, which can not be generalized in a simple fashion. But Japanese believe that silence is gold. They hate chatter and those who defend themselves. So if silence occurs, the interpreter should judge from the situation, and anticipate according to the context.

What's more, the Japanese take sincerity very seriously in negotiation, but Chinese companies tend to emphasize country's support or government background, which Japanese takes as the disrespect for market. In addition, during the negotiations, some inappropriate physical actions are also considered a kind of disrespect for them, such as leg-crossing.

\section{Conclusion}

Business Japanese interpretation is a cross-cultural communication commonly occurring in Sino-Japanese trades, and proficiency in the two languages is only one aspect of to make excellent interpretation. Interpreters should be familiar with Japanese business etiquettes, business people's body languages and facial expressions in order to discover the cultural loss on the levels of verbal, idiomatic expression and nonverbal communication, so as to rebuild the cultural elements lost in source language effectively and express them to target listeners. The success of business affairs largely depends on whether the interpretation can send the messages of the speakers, so it's essential for interpreters to be familiar with the cultures of two countries. 


\section{Acknowledgements}

The paper is a partial result of the research program "Foreign Literature: Culture and Translation" (program no. FRF-BR-15-016B) in the University of Science and Technology Beijing, funded by the

Ministry of Finance and Education, under the basic academic fund for Central Higher Education Institutions.

\section{References}

[1] Wang, X. The Translator's Multi-dimensional Cultural Attitude and Its Impact on the Process of Translation [J].Chinese Translators Journal, 2014(4):21.

[2] Li, Q. Non-verbal Communication and Paralanguage [J]. Journal of Japanese Language Study and Research, 2008(6):15.

[3] $\mathrm{Bi}$, J. Intercultural Non-verbal Communication [M]. Beijing: Foreign Language Teaching and Research Press, 2004:6.

[4] $\mathrm{Hu}, \mathrm{W}$. Culture and Communication [M]. Beijing: Foreign Language Teaching and Research Press, 1998.

[5] Wang, D. Cultural Default and Coherence Reconstruction in Translation [J]. Journal of Foreign Languages, 1997(6):55.

[6] Hiejima, Y. Psychology of Speech [M]. Tokyo: North Tree Publishing,1994. 